ISSN 2236-0859

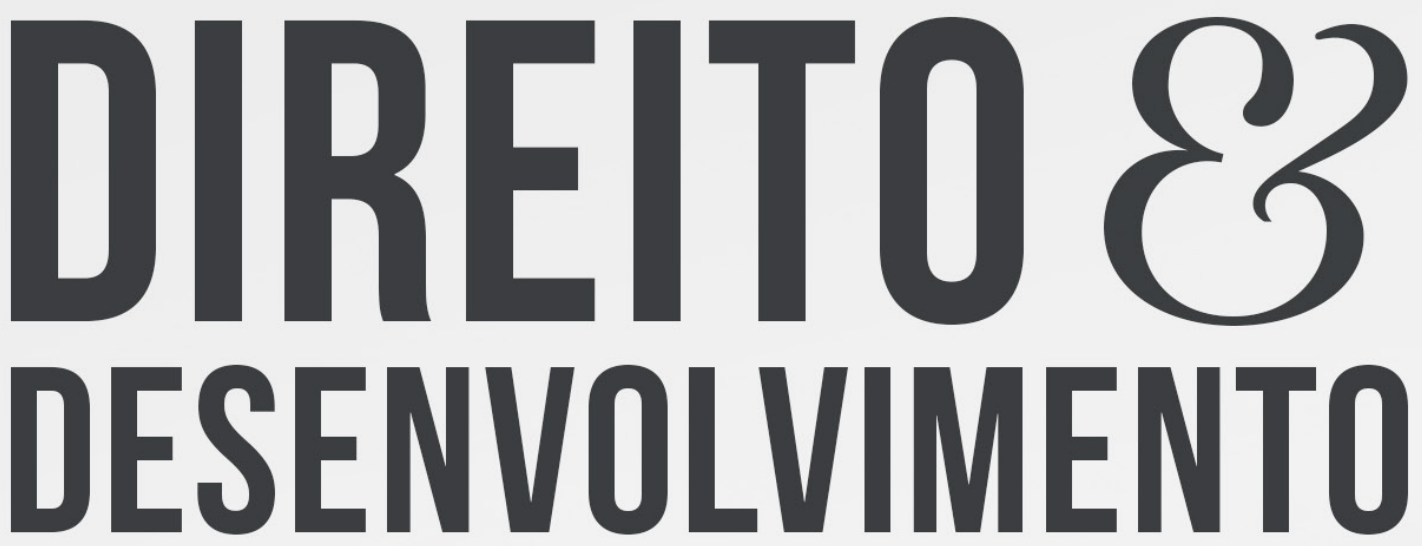

REVISTA DO PROGRAMA DE PÓS-GRADUAÇÃO EM DIREITO MESTRADO EM DIREITO E DESENVOLVIMENTO SUSTENTÁVEL

EVOLUÇÃO DOS MEIOS ADEQUADOS DE SOLUCÃODOS CONFLITOS AOS SERVIÇOS NOTARIAIS E DE REGISTRO

FELICIANO ALCIDES DIAS

ALICE BRITES OSÓRIO DE OLIVEIRA 


\title{
EVOLUÇÃO DOS MEIOS ADEQUADOS DE SOLUÇÃO DOS CONFLITOS AOS SERVIÇOS NOTARIAIS E DE REGISTRO
}

\section{EVOLUTION OF APPROPRIATE MEANS OF SETTLEMENT OF CONFLICTS TO NOTARY AND REGISTRATION SERVICES}

Recebido: 22/03/2018

Aprovado: 30/05/2019
Feliciano Alcides Dias ${ }^{1}$

Alice Brites Osório de Oliveira²

\section{RESUMO:}

No contexto da necessidade de incentivar os meios adequados de solução de conflitos como alternativas às vias judiciais, encontra-se a possibilidade de implementação da conciliação, mediação e arbitragem como nova função nos serviços notariais e registrais. Assim, objetivase através do método dedutivo com base na revisão bibliográfica, identificar similaridades e compatibilidade entre seus institutos, principalmente, pelos seus atores atuarem como auxiliares da justiça e serem considerados instrumentos de pacificação social.

Palavras-chave: Acesso à justiça. Meios adequados de resolução de conflitos. Serviços notariais e de registro. Pacificação social.

\begin{abstract}
:
In the context of the need to encourage the alternative dispute resolution as alternatives to judicial procedures, there is the possibility of implementing conciliation, mediation and arbitration as a new function in notary and registry services. Thus, it is objectified through the deductive method based on the bibliographical review, to identify similarities and compatibility between its institutes, mainly, by its actors acting as auxiliaries of justice and to be considered instruments of social pacification.
\end{abstract}

Keywords: Access to justice. Alternative dispute resolution. Notary and registry services. Social pacification.

\section{INTRODUÇÃO}

As críticas e os questionamentos em relação às problemáticas que surgem no Direito e na sociedade direcionam indivíduos e instituições que se dispõem a colaborar com sua resolução a propor iniciativas de auxílio. Dentre as propostas de colaboração ao Poder Judiciário, se insere

\footnotetext{
1 Doutor em Direito Público pela Universidade do Vale do Rio dos Sinos - UNISINOS. Mestre em Ciências Jurídicas e Especialista em Direito Civil pela Universidade do Vale do Itajaí - UNIVALI. Professor Titular de Direito Civil e Direito Processual Civil do curso de Graduação e Pós-Graduação em Direito da Universidade Regional de Blumenau - FURB. Professor e Coordenador da Escola de Magistratura do Estado de Santa Catarina - ESMESC. Pesquisador na linha "Acesso à Justiça, Gestão de Conflitos e Organizações" vinculada ao Grupo de Pesquisa "Direitos Fundamentais, Cidadania \& Justiça" certificado pela FURB junto ao CNPq. Advogado. Árbitro. E-mail: diasfeliciano@gmail.com

2 Mestra em História do Direito e Resolução de Conflitos pela Université de Limoges - França. O mestrado foi desenvolvido em trabalho com o laboratorio de pesquisa OMIJ (Observatoire de Mutations Institutionnelles et Juridiques - Observatório de Mutações Institucionais e Jurídicas) e o IIRCO (Institut International de Recherche sur la Conflictualité - Instituto Internacional de Pesquisa sobre a Conflitualidade). E-mail: alicebrites@hotmail.com.
} 
a possibilidade de utilização dos meios adequados de resolução dos conflitos como função atribuída aos Serviços Notariais e de Registro.

Pretende-se através deste estudo, demonstrar a possibilidade de realização dos meios adequados de tratamento e resolução dos conflitos nos Tabelionatos e Registros em uma análise à compatibilidade de tais setores. Para tanto, inicialmente, apresenta-se a exposição da atual situação do Poder Judiciário brasileiro, cuja crise acentua-se dentre outras causas, pela morosidade e a ineficiência dos serviços jurisdicionais. Na contemporaneidade, há uma necessidade premente de desafogamento das vias judiciais e de reversão do quadro crescente da judicialização dos conflitos.

Em seguida, desenvolve-se uma proposta de implementação dos meios adequados de resolução de conflitos como nova atribuição aos serviços notariais e de registro, com o intuito final de reafirmar a importância de ambos os institutos na sociedade, bem como de buscar o efetivo acesso à justiça.

\section{JUDICIALIZAÇÃO DO CONFLITO PERANTE O PODER JUDICIÁRIO}

Nesse novo milênio, muitos foram os marcos regulatórios deflagrados à sociedade contemporânea. A tecnologia se atualiza constantemente e em velocidade espantosa, assim, as demais áreas tendem a mudar juntamente com essa evolução. Em todos os ambientes emerge a necessidade de acompanhar o ritmo acelerado da atualidade. O tempo, agora mais do que nunca, mostra-se um fator decisivo na vida das pessoas. Em questão econômica, por exemplo, o mundo dos negócios gira em torno dos próprios atos negociais. Por consequência, a economia afeta questões de desenvolvimento regional e assim por diante, propaga por uma rede que atinge direta ou indiretamente todas as partículas que compõem o mundo atual.

A praticidade que a contemporaneidade proporciona faz necessitar, cada vez mais, de um período temporal menor para realizar suas diversas tarefas cotidianas. Em decorrência disso, acostuma-se, evidentemente, a contar com que os setores (instituições e/ou organizações) que prestam serviços - sejam eles públicos ou privados - realizem suas atividades, de forma a ir ao encontro no mesmo ritmo em que ocorrem múltiplas relações consideradas complexas na sociedade atual, seja de qualquer natureza.

Não obstante, a velocidade é tamanha que em muitos ambientes, especialmente os da esfera pública, não possuem a aptidão e estrutura para acompanhar as expectativas e demandas sociais. Pode-se até mesmo dizer que, a modernidade, por ora, apresenta-se tão fluida e móbil quanto poderia descrever Bauman (2001, p. o8), escorre pelas mãos da sociedade e - por conseguinte - do amplo rol de setores de atendimento às necessidades sociais.

Estamos sedentos pela ideia de agilidade e por correr em direção ao futuro, sem embargo, nossa identidade brasileira ainda traz resquícios das características marcadas pela colonização portuguesa. Um dos resultados da opressão sofrida ao longo dos séculos, proveniente de um "passado econômico colonial-extrativista e à construção posterior de um sistema sociopolítico elitista, individualista e desumanizador", segundo Wolkmer (2008, p. 16) é o desenvolvimento de uma cultura, por consequência, litigante.

No decorrer dos anos, devido a diversos motivos, a chamada "cultura do litígio" acabou por implementada no Brasil. Em efeito, a principal linha de acomodação dos conflitos de interesse traduz-se na utilização das vias judiciais; o que fez com que a maioria das pessoas perdesse a capacidade de superar seus dissabores, tampouco de buscar uma forma de solução amigável ou negociada. 
É manifesto e constantemente comentado dentre os doutrinadores e profissionais do direito, que o Poder Judiciário passa por entraves. Figueira Junior (1999, p. 105) admite que "não é de hoje que se ouve falar que o processo civil brasileiro está em crise e que existe descompasso entre o instrumento e a rápida, segura e cabal prestação da tutela por parte do Estado-Juiz".

Cahali lembra que a crise em nosso sistema judiciário decorrente, por exemplo, da morosidade processual, ainda que constatado seu alto custo. (CAHALI, 2011, p. 21). Por outro lado, Cappelletti e Garth (1988, p. 93) reconhecem que tal sistema é destinado a servir pessoas comuns, sejam elas autoras ou rés e, portanto, deveria ser reconhecido "[...] pelos baixos custos, informalidade e rapidez, por julgadores ativos e pela utilização de conhecimentos técnicos bem como jurídicos".

Tais afirmações apresentam-se como amostra de um elenco incalculável de autores brasileiros que atestam a real situação em que se encontra o Poder Judiciário. Registre-se que os motivos mencionados acima acerca da crise no Judiciário são apenas exemplificativos, visto que há vasto conteúdo doutrinário enumerando diversos outros. Isso se dá, na opinião de Santos, por tratar-se de fenômeno verdadeiramente complexo, já que não estão envolvidos somente os fatores econômicos, mas também os sociais e culturais "resultantes de processos de socialização e de interiorização de valores dominantes muito difíceis de transformar". (SANTOS, 1999, p. 171)

Nesse caso, não cabe aqui analisar todos os possíveis fatores que compõem a temática, mas prefere-se apresentar uma breve contextualização, nos limites pertinentes ao assunto principal deste estudo. Pesquisas de dados também reconhecem a obrigação, por parte do Poder Judiciário, de acompanhar e satisfazer as necessidades sociais pertinentes ao EstadoJuiz. Os últimos anos foram marcados por crescimento em relação ao número de processos em trâmite e, apesar das tentativas de diminuir os índices de litigiosidade, esta ainda se apresenta evidente no panorama social do país.

Através desses dados, é possível verificar que o conhecimento acerca dos meios adequados de solução de conflitos ainda não abrange toda a população, mas somente determinado perfil de cidadão. Ainda a tratar de indicadores do desempenho do Poder Judiciário, mister é mencionar as pesquisas realizadas pelo Conselho Nacional de Justiça, que dispôs no mais recente anuário denominado Justiça em Números (ano de 2016), pesquisa de dados coletados no ano de 2015. Nele, além de tratar dos resultados apresentados a respeito do ano-base de 2015, o anuário também faz referência à análise dos resultados obtidos na década de pesquisas anuais, referindo-se que em 2014, o número de processos era de 100 milhões e no ano de 2015 chegou a órbita de mais de 102 milhões. (BRASIL, CNJ, 2016, p. 17)

O referido relatório confirma os elementos da problemática apresentada pela crescente judicialização em nosso país e, ainda, reconhece que a grande maioria das estatísticas judiciais apresentadas remete a repetidos diagnósticos de morosidade, congestionamento das vias judiciais e de crise no sistema. A partir deste último relatório, o CNJ passou a computar em seus dados estatísticos a soma dos casos baixados e pendentes em tramitação no Judiciário, sendo que antes se referia à soma dos casos novos e pendentes. Por este motivo, tentativas de reverter o quadro litigioso foram pautadas no decorrer dos últimos dez anos, em forma de ações políticas e diversas propostas de soluções.

No que tange ao combate à morosidade, segundo o texto do relatório, as próprias pesquisas direcionadas a coleta de dados dos relatórios anuais foram aperfeiçoadas ao longo dos anos, objetivando a precisão das informações e a eficiência em tratar os problemas apresentados. Investiu-se, também, na implementação do processo judicial eletrônico, a fim de reduzir custos e morosidade processual, garantindo assim o direito à razoável duração do processo e a celeridade de sua tramitação. 
A utilização dos recursos eletrônicos no âmbito do Poder Judiciário representa uma aproximação deste órgão com a sociedade e suas tecnologias. As iniciativas tomadas pelo Conselho Nacional de Justiça para aperfeiçoar o diagnóstico apresentado também representam notáveis avanços. Ainda assim, o Poder Judiciário reconhece que é necessário dar continuidade à busca de soluções e meios eficazes e céleres de combate à vagareza e litigiosidade.

$\mathrm{O}$ interesse e os cuidados em trabalhar na melhoria das estatísticas colhidas ao longo dos últimos dez anos são evidentes na conclusão do relatório, em que se compreende o desdobramento das composições interinstitucionais em parte por meio da priorização das políticas de desmonopolização e de desenvolvimento das estratégias que reduzam o congestionamento dos conflitos judicializados. (BRASIL, CNJ, 2016)

No mesmo sentido se apresenta a concepção de Cappelletti e Garth (1988, p. 12), considerando que é preciso que os juristas reconheçam a função social das técnicas processuais, afinal, essas vias judiciais não representam a única forma para a solução de controvérsias.

Nota-se, portanto, a constante preocupação por parte do Judiciário em conferir efetividade ao acesso à justiça. Entretanto, como visto acima, o quadro apresentado pelo judiciário brasileiro é de morosidade e significativo número de processos ainda em trâmite, em contraposição às garantias constitucionais de duração razoável do processo e de acesso à justiça. Tendo em vista esta problemática, convém lembrar as sábias e atemporais palavras de Rui Barbosa (1947, p. 70), "a justiça atrasada não é justiça, senão injustiça qualificada e manifesta".

Com o advento da Emenda Constitucional no 45/2004, foram alterados diversos dispositivos constitucionais, dentre eles a inserção do inciso LXXVIII no artigo $5^{\circ}$ da Constituição Federal, compreendendo a primazia pela duração razoável do processo.

Por sua vez, o conteúdo do artigo $5^{\circ}$, inciso XXXV da Constituição Pátria foi compreendido não apenas como acesso ao sistema jurídico, ou ao processo judicial, mas sim, de modo a significar acesso à ordem jurídica justa. Implica em considerar que tanto o indivíduo quanto a coletividade possam sentir-se respeitados e satisfeitos com o resultado da observância aos seus direitos fundamentais.

Cappelletti e Garth, em suas palavras, atribuem valor ainda mais intenso ao acesso à justiça, pois compreendem que este é o mais básico dos direitos humanos, sendo elementar tê-lo como requisito fundamental de um "sistema jurídico moderno e igualitário que pretenda garantir, e não apenas proclamar os direitos de todos”. (CAPPELLETTI, 1988, p. 12)

Talvez um dos motivos pelo qual se possa considerar tamanha importância advinda do direito em questão encontre-se nas palavras de Santos (1999, p. 167), ao considerar que o direito ao acesso à justiça é "um direito cuja denegação acarretaria a de todos os demais". Em tal reflexão, pode se observar que restringir a dimensão da análise da efetividade do termo apenas com a interpretação de acesso às vias judiciais, de forma alguma abrangeria seu pleno significado. Entretanto, é importante diminuir as insatisfações da população, que desestabilizam a credibilidade no sistema judiciário brasileiro.

Nesse contexto, tanto a doutrina quanto pesquisas baseadas em dados reconhecem em unanimidade a existência de falhas no Poder Judiciário. Através desses reconhecimentos, existe igualmente a manifestação de vontade em melhorar o quadro atual, em respeito e sentimento de obrigação em cumprir garantias fundamentais de duração razoável do processo e o acesso a todos à justiça.

Para tanto, entendem-se como válidas as tentativas de encontrar soluções através de procedimentos em que não necessariamente esteja presente a figura do juiz, como em assistência do setor extrajudicial através de mediação, conciliação ou arbitragem. 
Em breves palavras, na mediação e na conciliação, enquanto métodos autocompositivos, verificam-se a participação fundamental das partes na tentativa de solução do conflito e a figura do terceiro imparcial como facilitador da comunicação. Na mediação, o terceiro atua como facilitador para a retomada do diálogo entre os envolvidos, que em geral, já possuem vínculo mais sólido. (CAHALI, 2011, p. 55). Justamente por se tratar de relação mais prolongada, a mediação necessita de mais de uma sessão para o tratamento do conflito, tendo em vista a necessidade de tempo maior para que se conheçam os elementos do problema em questão.

Na conciliação, a relação entre os envolvidos é geralmente circunstancial e derivada do conflito em foco. O foco principal, portanto, não está na continuidade da relação entre as partes, mas sim, o término do litígio. Assim, a conduta do conciliador direciona-se a esse propósito, já que o único vínculo que possuem as partes geralmente está ligado ao conflito. (BACELLAR, 2012, p. 67)

A arbitragem como meio heterocompositivo é considerada um método adversarial, em que as partes conflitantes submetem a decisão do litígio a um terceiro ou colegiado, imparcial e previamente eleito pelas mesmas. "A participação das partes, neste instrumento, volta-se a formular pretensões e fornecer elementos que contribuam com o árbitro para que este venha a decidir o litígio". (CAHALI, 2011, p. 36)

Evidentemente, existem diversos casos em que o processo judicial é o meio adequado a solucionar os litígios, e nesses, ele deve prestar amparo a todos que a ele recorrem. Entretanto, em muitas outras situações os meios adequados de solução de conflitos revelam ser a melhor opção para os interessados, assim como também exercem importante papel preventivo e de pacificação. Não restam dúvidas de que o Poder Judiciário não só pode como está aberto, a receber propostas de cooperação à resolução de conflitos por meios extrajudiciais.

Além das inovações legais diversas propostas surgiram, em especial, de instituições que se prontificaram a auxiliar de alguma forma o Poder Judiciário em prevenir ou tratar os conflitos de forma extrajudicial. Dentre elas, surge por iniciativa da Associação de Notários e Registradores do Brasil, a intenção de implantar meios adequados de tratamento e solução das controvérsias como nova atribuição no âmbito de seus ofícios.

Com essa nova implementação, as partes quando em desacordo, teriam a possibilidade de procurar um Ofício de Registros ou Tabelionato para solucionar o impasse, sem a necessidade de recorrer ao Judiciário para tal. No procedimento proposto, "as partes iriam ao cartório e apresentariam o impasse ao titular, escrevente ou juiz de paz". O profissional, devidamente capacitado para a realização de mediação ou arbitragem, cumpriria o procedimento. (VIEIRA, 2013, p. 41-44)

Após a contextualização da situação atual da justiça no Brasil, passa-se à apreciação da proposta em foco. Para tanto, explorar-se-ão sua viabilidade e os obstáculos dessa possível implementação.

\section{O INCENTIVO À DESJUDICIALIZAÇÃO DAS CONTROVÉRSIAS EM MATÉRIA REGISTRAL E NOTARIAL}

O artigo 236 da Constituição da República Federativa do Brasil de 1988 traz inovações desde sua publicação, conferindo aos titulares dos serviços notariais e de registro o ingresso na atividade por delegação do Poder Público.

Com essa peculiaridade, a motivação notarial e registral advêm da fé pública, de modo que o notário e o oficial de registro "[...] são hábeis e competentes, nos limites da atribuição 
que lhes foi conferida, para imporem através de seus atos e declarações a fé coercitivamente ao corpo social". (PUGLIESE, 1989, p. 70)

Seus serviços, portanto, são de estimado valor e função social. Também descritos como instituição de direito público, pois tais serventias são dotadas da função necessária a transmitir à população a sinceridade essencial ao equilíbrio social.

Da mesma forma, reconhece Sander (2005, p. 53) o desenvolvimento do raciocínio apresentando a fé pública do notário como "uma das mais amplas já conhecidas". É que na figura do notário - e assim também se dá com o registrador - se encontra a confiança por parte da população de que, com exceção à incontestável prova em contrário, o conjunto de atos por ele realizados são verdadeiros, corretos e autênticos.

Faça-se a ressalva, ainda, de que é de natureza do notariado latino a segurança jurídica reforçada de que são revestidos os instrumentos notariais. O notariado brasileiro possui também as características já mencionadas de conselheiro, visto que no exercício de suas funções, o notário desenvolve a assessoria jurídica imparcial das partes. (RODRIGUES, 2014, p. 221, 232).

Para os meios adequados de solução de conflitos, significativa importância reside no fato de haver profissional dotado de fé pública e reconhecimento social que possua também imparcialidade e habilidade de aconselhar juridicamente aqueles que buscam seus serviços, já naturais à sua profissão original. Sem esforço, essas características estão presentes na figura daqueles que exercem função notarial e registral.

O procedimento contaria com a imparcialidade e com a habilitação técnica do notário e registrador, que dotado de fé pública, pode garantir segurança jurídica a decisão. A homologação do acordo seria registrada em ata notarial, finalizando o procedimento. Não seria preciso que as pessoas contratassem advogados e que enfrentassem longas sessões judiciais. (VIEIRA, 2013, p. 42)

Encontra-se também no notário brasileiro o caráter autenticante, afinal, seu titular “[...] confere poder certificante, derivado da fé pública que dispõe, aos atos praticados por ele no exercício de suas atribuições legais". (RODRIGUES, 2014, p. 232)

Além de características da esfera pública, há ainda na atividade notarial e registral os privilégios do setor privado, em especial a agilidade. A velocidade do mundo privado influencia e colabora com a facilitação de circulação de riquezas, motivo pelo qual muitos dos que interagem com o ramo empresarial optam por resolver, dentro do possível, seus conflitos por vias extrajudiciais.

No desempenho de seu papel, espera-se que o notário - e igualmente o registrador - prestem serviços significativos também para os sistemas político e econômico. $\mathrm{O}$ que proporciona esse valor ao titular notarial ou registral é sua habilidade em atuar em um plano de "possibilidades reduzidas, específicas e de baixa complexidade", fazendo com que sua função seja diferenciada, ao mesmo tempo em que de certa forma se relaciona com as funções econômicas e políticas (CAMPILONGO, 2014, p. 17) e facilita a circulação de créditos. (SOUZA, 2011, p. 252)

A relação notarial e registral com a função econômica, de modo a atuarem de forma célere interessa àqueles que buscam nos meios adequados de solução de conflitos a agilidade muitas vezes não propiciada pelo Judiciário.

Dentre os diversos princípios pertinentes ao direito notarial e registral, e aqueles referentes aos meios adequados de solução e tratamento de controvérsias, analisar-se-á dois princípios relevantes ao estudo da temática proposta. São eles, o princípio da imparcialidade e o princípio da publicidade. 
Os meios adequados de solução de conflitos pressupõem que aquele que atuar como conciliador, mediador ou árbitro seja pessoa imparcial. Isso se dá tanto pelo próprio princípio de imparcialidade, comum às três atividades, quanto pelos regulamentos próprios existentes, a citar, por exemplo, o artigo 13, parágrafo 6o da Lei no 9.307 de 1996, também conhecida como Lei de Arbitragem, com as recentes alterações pela Lei no 13.129/2015 que além de propiciar a ampliação de seu campo de atuação, modernizaram o referido instituto.

Ao atuarem como árbitros, mediadores ou conciliadores, o notário e o registrador da mesma forma adotariam postura imparcial. A imparcialidade, contudo, já se faz presente nas atividades exercidas por esses profissionais, afinal, a função registral e notarial apresenta "[...] um caráter imparcial, uma vez que ao tabelião compete dirigir imparcialmente os indivíduos na busca regular de seus direitos subjetivos privados". (SANDER, 2005, p. 88)

Os resultados da imparcialidade dos notários e registradores em todas as suas atuais atividades ofereceriam complemento à atuação imparcial que se espera daqueles que atuam com meios adequados de solução de conflitos. Nesse sentido, a fusão de ambas as atividades representaria para os demandantes, atuação com clara exposição de "[...] riscos, opções e interesses colocados a cada parte, auxiliando a formação de expectativas quanto ao cumprimento do contrato". (CAMPILONGO, 2014, p. 91)

Quanto à publicidade, importa verificar que o direito notarial e registral apresentam, em todas as suas ramificações, íntima relação com esse princípio. Conforme já visto no corpo deste trabalho, o princípio da publicidade nas atividades notariais e registrais se faz presente como regra, permitindo algumas exceções.

Não se pretende estender demasiadamente no conceito de publicidade, mas é importante relembrar que este princípio, disposto no artigo 172 da Lei no $6.015 / 73$ e no artigo $1^{\circ}$ da Lei no 8.935/94, garante efeito erga omnes ao ato registral.

Os meios adequados de solução de conflitos, entretanto, possuem como princípio comum a confidencialidade. No caso da mediação e da conciliação, esse princípio é inclusive incorporado no novo Código de Processo Civil (Lei no 13.105/2015). No que tange ao instituto arbitral, ainda que a Lei de Arbitragem não exija que o procedimento seja confidencial, não raras as vezes a convenção arbitral dispõe sobre reserva de publicidade, sendo que mesmo os regulamentos das câmaras estabelecem tal regra. (CAHALI, 2011, p. 77). Em relação à arbitragem que envolva a administração pública, entretanto, respeitar-se-á o princípio da publicidade, de acordo com a recente alteração do artigo $1^{\circ}$, parágrafo $3^{\circ}$ da Lei da Arbitragem.

Para que não houvesse divergência principiológica entre os institutos, talvez deva se ponderar a confidencialidade na atividade de resolução de conflitos em âmbito notarial ou registral, como exceção ao princípio da publicidade cartorária.

Em quesito de confiabilidade, tomando a arbitragem como ponto de partida para a análise do tópico, pode-se observar através das palavras de Marinoni e Arenhart (2013, p. 362) que a eficácia desse instituto pressupõe a presença de confiança dos envolvidos: Somente assim o árbitro poderá realizar plenamente seu ofício, evitando ao máximo que a lide chegue às vias judiciais.

Da mesma forma que ocorre com o árbitro, considera-se que tanto o mediador quanto o conciliador, para o bom desempenho de suas funções, necessitam da confiança depositada pelas partes em sua figura e nesses institutos. Em comparação, é digno de nota que os serviços notariais e registrais espalhados por todo o país figuram entre as instituições com melhor avaliação nos quesitos "confiança" e "credibilidade", por se tratar de um serviço extrajudicial com fé pública. 
O caráter conselheiro que possui o notário brasileiro, aliado à confiança demonstrada pela sociedade nas atividades notariais e registrais, opera como complemento à necessidade de confiabilidade nos meios adequados de solução de conflitos.

\section{O DESENVOLVIMENTO DOS SERVIÇOS NOTARIAIS E REGISTRAIS EM PROL DA PACIFICAÇÃO SOCIAL}

É reconhecido pela doutrina que o notário e o registrador atuam como auxiliares da justiça. Como os atos praticados em suas serventias são de grande valor econômico, social e jurídico, de modo que propiciam segurança e certeza decorrentes de suas atribuições e previnem a formação de processos judiciais, são considerados, portanto, auxiliares na promoção da paz social. (SANDER, 2005, p. 109)

Os serviços notariais e registrais "representam relevante instrumento para alcance da paz social, à margem da atuação do Poder Judiciário”. É, definitivamente este, acentuado ponto em comum e de união entre serviços notarial e de registro e os meios adequados de solução de conflitos. (SOUZA, 2011, p. 252)

Em sua essência, o notário vincula características de árbitro extrajudicial, que se apresentam nítidas em relação ao conhecimento técnico em sua área de atuação. Atua também como conciliador quando auxilia as partes na decisão aspectos a serem reestruturados ou negociados.

A função notarial, então, possui caráter cautelar, tendo como resultado mecanismo preventivo de litígios. Através de sua natureza branda, os notários muitas vezes viabilizam a composição, impedindo que as desavenças alcancem as vias judiciais, "[...] não sendo considerado meramente um colaborador instrumental de preparação para futuros processos". (REZENDE, 2004, p. 32). É, portanto, da natureza de ambos - notário e registrador - a cultura apaziguadora, como assim o é nos meios adequados de solução de conflitos.

\subsection{Conhecimento jurídico do notário e do registrador}

O conhecimento jurídico aprofundado não é exigência apresentada na lei para os meios extrajudiciais de resolução de conflitos como a arbitragem. Entretanto, é válido considerar que aqueles que possuem conhecimento jurídico material e processual apresentam também mais facilidade em conduzir procedimentos similares aos judiciais.

Pode-se afirmar que notários e registradores, nesses termos, possuem vasto conhecimento jurídico nas áreas de sua atuação. Compreende-se que os setores de notas e de registros facilmente relacionam, em teoria e prática, o direito público com o direito privado, tendo em vista sua natureza de delegação pública e atuação como particulares. Em consequência, esses profissionais possuem peculiar habilidade de adaptação a possíveis inovações.

Em relação ao conhecimento técnico que se apresenta como característica de um árbitro é considerado que, "[...] pelo menos um dentre eles seja detentor de sólida formação jurídica, reconhecida cultura e saber, experiente, operoso e detentor da confiança de ambas". (FIGUEIRA JUNIOR, 1999, p. 197)

Sob outra perspectiva, o reconhecido conhecimento jurídico que os titulares de notas e de registros possuem é relacionado às especialidades e serviços de seus ofícios. Cada uma das oito especialidades do sistema notarial e registral brasileiro estende-se a assuntos distintos, o que por consequência leva seus funcionários a serem conhecedores de matérias específicas 
pertinentes às suas circunscrições. Os titulares e seus funcionários, portanto, possuem vasto conhecimento jurídico dentro das áreas em que atuam.

Entretanto, em caso de toda sorte de assunto ser destinada a qualquer setor específico dos serviços notariais e de registro, haveria, pelo menos de início, dificuldades em cada instância em resolver de forma hábil os conflitos daqueles assuntos de que o titular de um dos estabelecimentos não fosse especialista.

Aqui se encontra um contraponto ao já mencionado conhecimento técnico do árbitro, por exemplo. Em face disso, é possível ponderar se seria mais pertinente o titular arbitrar os casos condizentes ao seu ofício. Nessa perspectiva, a aptidão para resolver conflitos por ora limitar-se-ia a questões relacionadas ao conhecimento na área em que cada tabelião ou oficial de registro atua.

Naturalmente, as partes interessadas no procedimento arbitral dão preferência àqueles com melhor conhecimento em determinadas matérias. Na questão levantada, dois pontos seriam considerados: o valoroso conhecimento técnico e jurídico que os notários e registradores possuem em sua área de atuação, todavia aprofundado apenas nela; e a possibilidade de haver ou não a faculdade de escolher os assuntos aos quais arbitrar, dado seu conhecimento técnico.

\subsection{Questões procedimentais}

No que diz respeito ao procedimento, os meios adequados de solução de conflitos têm em sua fase final a lavratura de documento que registra o acordado entre as partes (no caso dos métodos autocompositivos) ou o determinado por terceiro (no caso da heterocomposição). Dentro da possibilidade aqui estudada, o documento final seria lavrado no próprio estabelecimento registral ou notarial, com fé pública, autenticação, de maneira célere e com redução de burocracia. (VIEIRA, 2013, p. 42). Será documento final produzido pelo profissional mais capacitado a transcrever com exatidão a vontade das partes, pois esta é a essência de sua função diária.

Vale a ressalva, entretanto, de que se deve ponderar o papel do notário e do registrador nos momentos em que se pese a atuação de mais de um árbitro ou mediador, caso esta seja a preferência das partes interessadas. Na natureza notarial brasileira, por exemplo, é ignorada, em tese, a organização colegiada oficial. (RODRIGUES, 2014, p. 231)

A legislação brasileira versa sobre a possibilidade de, em determinadas circunstâncias, mais de uma espécie de serviço notarial ou registral recair sobre a mesma pessoa. Todavia, a lei trata dos titulares das atividades de notas e registros na forma singular, especificando que não podem dois profissionais titulares atuarem dentro de uma mesma circunscrição.

Na utilização dos meios adequados de solução de conflitos como tarefa implementada aos sistemas notariais e de registro, cabe ponderar se o titular receberia, então, outros profissionais para compor o conselho de arbitragem ou mediação. Questiona-se ainda, se em hipótese de as partes optarem por mais de um notário ou registrador na composição do conselho, este teria de se deslocar de seu ofício para atuar em outro. Caso se aplique o princípio da territorialidade, pertinente aos serviços de notas e de registros, em regra o titular não poderia atuar em outro ofício que não o de sua circunscrição. 


\subsection{Estrutura dos serviços notariais e de registro voltados aos meios adequados para a gestão de conflitos}

Tradicionalmente, a sociedade brasileira tem o hábito de recorrer diretamente ao Poder Judiciário para obter a resolução de conflitos, não sendo os meios adequados de solução de conflitos amplamente utilizados ou devidamente conhecidos por toda a população.

Todavia, tratando-se de quesito histórico, os serviços notariais e registrais já de séculos possuem tradição e "estão os serviços em foco em constante evolução: legislativa, na preparação de seus profissionais, no seu estudo, na participação na vida dos cidadãos". (SOUZA, 2011, p. 253). Por se fazerem presentes em todas as etapas da vida de cada cidadão, são ambientes e serviços conhecidos por toda a população brasileira, independente de classe econômica ou outros divisores sociais.

Além dos serviços neles prestados, os Tabelionatos e Registros são também conhecidos por toda população porque existem em todos os distritos brasileiros, diferentemente dos Juizados Especiais. Conforme o posicionamento do Presidente da Anoreg-BR sobre os municípios em que ainda não foram instituídos os Juizados Especiais, “[...] o cidadão não vai precisar viajar até um centro maior para resolver conflitos. Todos os distritos e municípios brasileiros poderão ter um sistema de mediação e arbitragem dentro do cartório". (VIEIRA, 2013, p. 43)

Os ofícios registrais e notariais, inclusive, representam o órgão mais numeroso do país, justamente pela obrigatoriedade legal de haver pelo menos um ofício em cada cidade brasileira. Ao ponderar tal informação, é válido lembrar que a real abrangência acesso à justiça, ainda muito centrado no Poder Judiciário, é desconhecida pela população brasileira, que consequentemente desconhece seus direitos. (CAOVILLA, 2003, p. 33-34). O posicionamento de outros meios de resolução dos conflitos, que não o litigante através do Judiciário, em ambiente já conhecido e reconhecido pelos indivíduos reafirma o valor e a efetividade do acesso à justiça.

Contudo, há que se considerar que nosso país conta com vasto território, onde se fazem presentes as mais variadas realidades culturais, econômicas e sociais, fator que reflete também na realidade dos serviços notariais e registrais de cada região. A possibilidade suscitada provavelmente não prestaria grande auxílio aos ofícios de grandes municípios. Em determinados locais, tal implementação poderia prejudicar o atendimento da demanda já existente.

Cabe considerar que os tabelionatos e registros vêm ampliando suas atribuições desde o final da década de 1970, com leis que possibilitam a realização de determinados atos extrajudiciais em seus ofícios sem que isso constitua efetiva redução na problemática processual do Judiciário. Pelo contrário, os dados disponibilizados pelo Conselho Nacional de Justiça demonstram que o número de processos iniciados ou em trâmite apenas aumentou na última década. (AMADEI, 2014, p. 42)

A sobrecarga dos serviços nesse setor provavelmente afetaria, por consequência, na futura credibilidade relacionada à confiabilidade e atendimento, atualmente bem avaliados pela população. Em outras palavras, o que de fato poderia acontecer seria apenas uma transferência de sobrecarga de um setor - o Judiciário - para outro - os serviços de notas e registros.

Entretanto, conforme já mencionado, a realidade do país é diversa. Tanto existem serviços notariais e registrais assoberbados de afazeres e sem que lhes seja vantajoso a implementação de mais uma tarefa; como existe a realidade distinta, com determinados municípios em que os cartórios subsistem.

Há que se considerar que para certos municípios em situações menos prósperas, a implementação de nova atividade traria benefícios tanto para a população local como também para os titulares e funcionários dos serviços. Nesses termos, ainda é possível ponderar a questão 
econômica da proposta com análise dos serviços e da estrutura dos cartórios extrajudiciais. Observa-se que o sistema notarial do tipo latino historicamente apresenta "[...] elevada capacidade adaptativa às exigências da economia e das mudanças nos modelos de regulação estatal". (CAMPILONGO, 2014, p. 113)

Por decorrência das similaridades, algumas atividades de caráter preventivo são tacitamente realizadas nos registros e tabelionatos, afinal, em muitas ocasiões (casamentos, divórcios, compra de imóveis, entre outras), o tabelião ou oficial de registro instrui e esclarece às partes a previsão legal pertinente às situações em pauta. Nesse contexto, tem-se que "aplicação da Lei de Arbitragem por vezes exige que o interesse se socorra pelos mencionados serviços, e por vezes permite a sua utilização, o que é de todo recomendável, por serem serviços que conferem publicidade, autenticidade, segurança e eficácia aos atos praticados". (SOUZA, 2011, p. 253)

Deste modo, poderia ser aproveitada a estrutura dos tabelionatos e registros existentes em todas as cidades brasileiras, assim como, o conhecimento que possuem as pessoas da existência dos cartórios extrajudiciais para neles incluir as atividades de conciliação, mediação e arbitragem. Ao se visualizar essas atividades aproximadas em um mesmo local, haveria ainda mais praticidade no que diz respeito à documentação. Os serviços do tabelião e do registrador far-se-iam presentes em todos os momentos em que se fizesse necessária a utilização de documento escrito. Tal atitude minimizaria a burocratização dos procedimentos.

Vale, ainda, ponderar sobre o custo para a implementação dos meios adequados de solução de conflitos nos serviços registrais e notariais. Para os oficiais de registro e os tabeliães, seria necessário mais investimento em espaço para a realização dos procedimentos de solução de conflitos - como disponibilizar no mínimo uma sala própria para esta atividade - bem como o investimento para sua manutenção, no que se relaciona a energia, funcionários, entre outros dispêndios.

Em contrapartida, também os serviços arbitrais dispenderiam de custos; valores estes que caso se exceda não representariam incentivos ao acesso à justiça por meio extrajudicial tendo em vista que, apesar de morosa em relação ao serviço de caráter privado, as vias judiciais dispõem da possibilidade de acesso gratuito.

Ainda deve ser considerada, a partir das premissas apontadas, a forma como seria realizada essa nova atribuição, se opcional ou facultativa aos serviços notariais e de registro. E mesmo, quem - titular, escrevente e/ou demais funcionários - exerceria papel de árbitro, conciliador ou mediador nas circunscrições.

Seriam, portanto, necessárias determinadas modificações nas leis que regulamentam as atividades em foco, levando em consideração muitos dos aspectos aqui levantados e ainda, provavelmente, muitos outros. Contudo, apesar de possíveis entraves ou dificuldades, é válido lembrar as dignas palavras de Watanabe (2014) referindo-se a Justiça como obra coletiva, em que "[...] a boa organização da Justiça não depende só do Poder Público, depende da participação da sociedade. A sociedade não pode ser tão dependente do Estado na resolução dos conflitos, tem de ter mecanismos próprios para solucionar as disputas".

O que se pode afirmar é que é elogiável toda atitude que busque incentivar e colaborar com a construção de uma cultura mais pacífica e humana no Brasil, com a preocupação em rever a presente situação crítica do Poder Judiciário e a busca de pacificação através da promoção de meios adequados de tratamento e solução de controvérsias. 


\section{CONCLUSÃO}

As recentes inovações legais incorporadas pelo vigente Código de Processo Civil brasileiro e as alterações à Lei de Regência da Arbitragem pela Lei no 13.129/2015, representam o desejo de ampliar a utilização dos meios adequados de solução de conflitos.

Nota-se que é de iniciativa dos próprios serviços notariais e registrais a execução dessa atribuição. Tal iniciativa se adequa às perspectivas das mais recentes doutrinas e legislações brasileiras, que incentivam a busca pela implementação de forma mais efetiva dos meios adequados de resolução de conflitos.

Ao mesmo tempo, a realização da conciliação, da mediação e da arbitragem em instituição de delegação do Poder Público, lhes confere benefícios em questão de efetividade e segurança em seus procedimentos. E, ainda, pode se considerar que o reconhecimento dos serviços de notas e registros e seu alcance social em todos os municípios do país unir-se-iam ao propósito dos meios adequados de solução de conflito, assim como ao real significado de acesso à justiça, pela proporção de seu alcance.

Reconhece-se na instituição de notários e registradores, portanto, a importância das tentativas de se buscar através das vias extrajudiciais a resolução de problemas que, em uma perspectiva ampla, não são apenas judiciais, mas também sociais, que afetam tanto a coletividade quanto o indivíduo.

No anseio pela resolução da problemática comumente denominada por diversos doutrinadores como "crise no sistema judiciário", encontram-se também a necessidade e as possibilidades de se evoluir em questão de transformação de uma cultura social litigante para a conduta de pacificação, ao mesmo tempo em que se pretende ampliar o acesso à justiça como direito fundamental digno de alcance a todos os brasileiros.

\section{REFERÊNCIAS}

AMADEI, Vicente de Abreu. Mediação e jurisdição voluntária como praticidade funcional do tabelião e do registrador. Revista Direito Notarial e de Registro, p. 41-46, maio. 2014. Disponível em: <http://www.youblisher.com/p/906769-Revista-de-Direito-Notarial-e-deRegistro/>. Acesso em: 25 nov. 2017.

BACELLAR, Roberto Portugal. Mediação e arbitragem. São Paulo: Saraiva, 2012. (Coleção Saberes do Direito no. 53 ).

BARBOSA, Rui. Oração aos moços. Rio de Janeiro: Simões, 1947.

BAUMAN, Zygmunt. Modernidade líquida. Rio de Janeiro: Jorge Zahar, 2001.

BRASIL. Poder Judiciário. Conselho Nacional de Justiça. Justiça em números 2o16: ano-base 2015. Conselho Nacional de Justiça - Brasília: CNJ, 2016.

BRASIL. Planalto. Constituição da República Federativa do Brasil, de 05 de outubro de 1988. Disponível em: <http://www.planalto.gov.br/ccivil_03/constituicao/constituicao.htm>. Acesso em: 20 jun. 2017 
BRASIL. Planalto. Lei no 9.307 de 23 de setembro de 1996. Dispõe sobre arbitragem. Disponível em: <http://www.planalto.gov.br/ccivil_03/leis/L9307.htm>. Acesso em: 20 jun. 2017.

BRASIL. Planalto. Lei no. 13.105, de 16 de março de 2015. Código de processo civil. Disponívelem:<http://www.planalto.gov.br/ccivil_03/_ato2015-2018/2015/lei/l13105.htm.> Acesso em: 20 jun. 2017.

BRASIL. Planalto. Lei no. 13.129 de 26 de maio de 2015. Altera a Lei no 9.307, de 23 de setembro de 1996, e a Lei no 6.404, de 15 de dezembro de 1976, para ampliar o âmbito de aplicação da arbitragem e dispor sobre a escolha dos árbitros quando as partes recorrem a órgão arbitral, a interrupção da prescrição pela instituição da arbitragem, a concessão de tutelas cautelares e de urgência nos casos de arbitragem, a carta arbitral e a sentença arbitral, e revoga dispositivos da Lei no 9.307, de 23 de setembro de 1996. Disponível em: <http://www.planalto.gov.br/ ccivil_03/_Ato2015-2018/2015/Lei/L13129.htm>. Acesso em: 20 jun. 2017.

CAHALI, Francisco José. Curso de arbitragem. São Paulo: Revista dos Tribunais, 2011.

CAMPILONGO, Celso Fernandes. Função social do notariado: eficiência, confiança e imparcialidade. São Paulo: Saraiva, 2014.

CAOVILLA, Maria Aparecida Lucca. Acesso à justiça e cidadania. Chapecó: Argos, 2003.

CAPPELLETTI, Mauro; GARTH, Bryant. Acesso à justiça. Tradução de Ellen Gracie Northfleet. Porto Alegre: Sergio Antonio Fabris, 1988.

FIGUEIRA JUNIOR, Joel Dias. Arbitragem: jurisdição e execução. Análise crítica da Lei 9.307, de 23.09.1996. São Paulo: Revista dos Tribunais, 1999.

MARINONI, Luiz Guilherme; ARENHART, Sérgio Cruz. Curso de processo civil: procedimentos especiais. 4. ed. São Paulo: Revista dos Tribunais, 2013. v. 5.

PUGLIESE, Roberto J. Direito notarial brasileiro. São Paulo: Leud, 1989.

REZENDE, Afonso Celso. Tabelionato de notas e o notário perfeito. 3. ed. Campinas: Millenium, 2004. .

RODRIGUES, Marcelo Guimarães. Tratado de registros públicos e direito notarial. São Paulo: Atlas, 2014.

SANDER, Tatiane. Atividade notarial como função de justiça preventiva. São Leopoldo: Oikos, 2005.

SANTOS, Boaventura de Souza. Pela mão de Alice: o social e o político na pós-modernidade. 6. ed. São Paulo: Cortez, 1999.

SOUZA, Eduardo Pacheco Ribeiro de. Noções fundamentais de direito registral e notarial. São Paulo: Saraiva, 2011. 
VIEIRA, G. (Org.). Cartórios: da pena à era digital - a atividade notarial e registral no século XXI. p. 41-44, nov. 2013. Disponível em: <http://www.youblisher.com/p/824376-Cartoriosdapena-a-era-digital/>. Acesso em: 15 out. 2017.

WATANABE, Kazuo. Sociedade não pode ser tão dependente do Estado para resolver conflitos. Revista Consultor Jurídico. 9 nov. 2014. Disponível em: <http://www.conjur.com.br/2014nov-og/entrevista-kazuo-watanabe-advogado-desembargador-aposentado-tj-sp>. Acesso em: 15 out. 2017.

WOLKMER, Antonio Carlos; VIEIRA, Reginaldo de Souza (Org.). Estado, política e direito: relações de poder e políticas públicas. Criciúma: UNESC, 2008. 